\title{
Construção de um micrótomo de congelamento a partir da adaptação de um micrótomo de parafina
}

\author{
Cesar de Mello ${ }^{1}$, L. Silva ${ }^{1}$, D. A. M. Zaia ${ }^{2}$ and Cassia Thais B. V. Zaia ${ }^{* 3}$ \\ ${ }^{1}$ Divisão de Equipamentos-PCU, ${ }^{2}$ Departamento de Química, ${ }^{3}$ Departamento de Ciências Fisiológicas, \\ Universidade Estadual de Londrina, 86051-990 Londrina-PR, Brazil
}

\begin{abstract}
A microtome for frozen sections was developed using the facilities and equipment available in our country. The requirements for making it were: 1) fast frozen of the tissue, 2) easy histological procedure, 3) no necessity of long period for preparation of the tissue for histological procedure, and 4) low cost for making. This study shows results obtained by using the microtome for frozen sections of brain of rats.
\end{abstract}

Key words: Frozen section, Microtomy, Frozen microtome

Palavras chaves: Cortes de congelamento, Microtomia, Micrótomo de congelamento

\section{INTRODUÇÃO}

Experimentos que utilizam, para o procedimento histológico, a técnica de inclusão em parafina, requerem um período longo de processamento da peça até sua análise final (Michalany, 1980).

Muitas vezes, há necessidade de se fazer um acompanhamento histológico durante o decorrer do experimento, principalmente no caso de cirurgias estereotáxicas em animais experimentais, onde a avaliação do local de manipulação no cérebro é fundamental (Zaia, 1984; Zaia, 1991; Zaia et al., 1987; Zaia et al., 1997). A utilização da técnica de inclusão em parafina torna impossível este tipo de monitorização, pois tal procedimento é demorado, apresentando muitas etapas, e levando muitas vezes até 10 dias para o processamento total do material a ser analisado, no entanto, com um micrótomo de congelamento seriam necessários no máximo 15 minutos (Akabayashi et al., 1993; Akabayashi et al., 1994, Akabayashi et al., 1994).

A necessidade de uma técnica mais rápida e as dificuldades na aquisição de um equipamento adequado, estimularam o desenvolvimento da adaptação de um micrótomo de parafina em um micrótomo de congelamento. $\mathrm{O}$ presente trabalho teve, portanto, como objetivo construir um sistema de congelamento para ser adaptado em um micrótomo de parafina, utilizando peças de baixo custo disponíveis no mercado nacional. Este equipamento foi testado utilizando cérebros frescos ou deixados por 24 horas em formol $4 \%$, cérebros estes obtidos de ratos submetidos à implantação de cânula para microinjeção de drogas no hipotálamo.

\section{MATERIAIS E MÉTODOS}

A partir de um micrótomo de parafina fez-se uma adaptação para obter-se um micrótomo de congelamento. A adaptação foi feita de forma a permitir que a base-suporte do micrótomo de parafina pudesse ser congelada ou descongelada rapidamente.

Peças utilizadas para a construção do sistema de congelamento: Foi utilizado um micrótomo de parafina cuja base-suporte, para sustentação do bloco de parafina, foi modificado fazendo-se uma conexão com a

\footnotetext{
* Autor para correspondencia
} 
tubulação por onde passa o gás de refrigeração (Fig. 1, Fig. 2). Utilizou-se, também, um compressor de geladeira de 1/8 HP, um condensador $1 / 8$, um micromotor $1 / 25$, gás freon-12, duas válvulas solenóides com entrada e saída de $1 / 4$, um pressostato de baixa, uma chave magiros de três posições, uma chave magiros de duas posições, 3 lâmpadas de neon tipo olho de boi, um condensador eletrolítico de $145 q$ (175 $\mu$ faradeis $\mathbf{x} 160 q, 160$ volts).

Funcionamento do sistema de congelamento: $\mathrm{O}$ gás freon é bombeado através do compressor de 1/8 HP, para o condensador de aletas de $1 / 8$, ocorrendo o resfriamento do gás, em seguida passa pelo filtro de gás para a remoção de umidade contida no mesmo, seguindo então para a válvula solenóide "congela", que estará ligada dando passagem para o gás; em seguida o gás é forçado a passar pelo tubo de $2 \mathrm{~mm}$ "capilar", seguindo então para o congelador instalado no micrótomo; no congelador, o gás sofre uma descompressão, pela passagem do tubo de $2 \mathrm{~mm}$ para o tubo de $6 \mathrm{~mm}$, resultando em resfriamento, em seguida, retorna ao compressor para o início de um novo ciclo (Fig. 1 e $2 B)$.

Funcionamento do sistema de descongelamento: $O$ gás é bombeado pelo compressor, seguindo para o solenóide de descongelamento, que estará ligado e dando passagem para o gás (solenóide de congelamento estará fechado); o gás segue para o congelador instalado no micrótomo, gerando calor dando a condição de descongelamento, em seguida retorna para o compressor repetindo o ciclo (Fig.1).

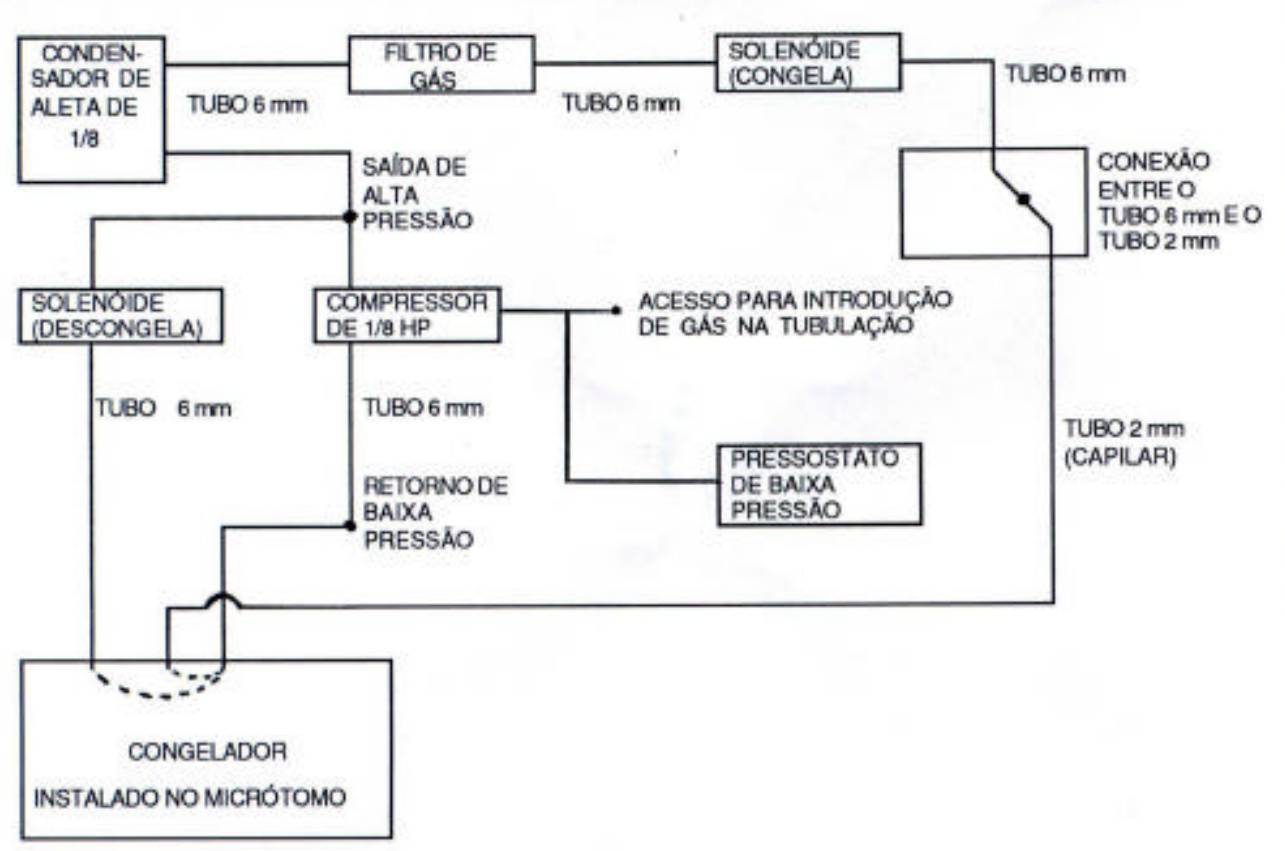

Fig. 1. Esquema em blocos do sistema de congelamento/descongelamento para adaptação em micrótomo de parafina.

Animais: Como teste deste aparelho, foram utilizados ratos adultos, Wistar, machos, pesando entre 250 e $300 \mathrm{~g}$, que foram submetidos à cirurgia estereotáxica, onde a cânula foi implantada no núcleo paraventricular do hipotálamo (PVN), sendo as coordenadas estereotáxicas $\quad(\mathrm{AP}=6,8 ; \quad \mathrm{H}=8,9 ; \quad$ e $\quad \mathrm{L}=0,4)$ baseadas em atlas de Paxinos e Watson (1986). Após a cirurgia, os animais foram mantidos em gaiolas individuais para posterior microinjeção de drogas. 
Figura 2. Micrótomo de congelamento adaptado. A. Sistema de congelamento conectado a micrótomo de parafina. B. Vista interna do sistema de congelamento e conexão com base-suporte. C. Base-suporte com cérebro fixado por congelamento.

Procedimento para obtenção do cérebro: Os animais, após as microinjeções, foram sacrificados por decapitação; o cérebro foi rapidamente removido e imediatamente colocado em solução de formalina $4 \%$. Em seguida o mesmo foi colocado em uma matriz de cérebro e as estruturas nervosas posteriores foram removidas através de um corte na posição mesencefálica. Com este procedimento, obteve-se uma superfície plana e simétrica, necessária para posicionamento do cérebro na base suporte do micrótomo (Fig. 2C).
Corte do cérebro: Utilizando o aparelho descrito neste estudo, os cérebros foram então submetidos à microtomia. Para tal, um pequeno pedaço de papel filtro embebido em salina $(0,9 \%)$ foi colocado na base-suporte do micrótomo, o cérebro foi posicionado sobre o papel e salina foi gotejada sobre o mesmo (Palkovits, 1973). Com o resfriamento da basesuporte (até $-6^{\circ} \mathrm{C}$ ) e o gotejamento de salina sobre o cérebro, rapidamente o mesmo foi fixado e congelado (Fig. 2A, Fig. 2C). Fatias de $40 \mu \mathrm{m}$ foram então obtidas. 


\section{RESULTADOS E DISCUSSÃO}

Com este aparelho obteve-se um resfriamento de até $-6^{\circ} \mathrm{C}$ da base-suporte, o que permitiu a fixação do cérebro com solução salina; esta temperatura foi suficiente para obtenção de rápido congelamento (Fig. 2C) da peça (3 minutos para $2 \mathrm{~g}$ de tecido cerebral) e cortes congelados com a espessura de $40 \mu \mathrm{m}$.

O presente aparelho mostrou ser de simples confecção, baixo custo e fácil utilização fornecendo cortes histológicos de boa qualidade. Através da construção deste aparelho, foi possível tornar mais rápido o trabalho de processamento de tecidos para análise histológica. Portanto, o referido aparelho atende às necessidades pretendidas podendo ser usado em histologia à fresco e está sendo utilizado por docentes pesquisadores e estagiários do laboratório de Neuroendócrino do Departamento de Ciências Fisiológicas da Universidade Estadual de Londrina.

\section{CONCLUSÃO}

O presente aparelho mostrou ser de simples confecção, baixo custo e fácil utilização fornecendo cortes histológicos de boa qualidade. Através da construção deste aparelho, foi possível tornar mais rápido o trabalho de processamento do tecido para análise histológica. Portanto, o referido aparelho atende às exigências requeridas podendo ser usado em histologia à fresco.

\section{AGRADECIMENTOS}

Dra.Cássia Thaïs B. V. Zaia agradece ao CNPq pela Bolsa de Pesquisador.

\section{REFERÊNCIAS BIBLIOGRÁFICAS}

Akabayashi, A.; Zaia, C.T.B.V.; Silva, I.; Chae, H.J. \& Leibowitz, S.F. (1993), Neuropeptide Y in the arcuate is modulated by alterations in glucose utilization. Brain Res., 621, 343-348.
Akabayashi, A.; Zaia, C.T.B.V.; Gabriel, S.M.; Silva, I.; Cheung, W.K. \& Leibowitz, S.F. (1994), Intracerebroventricular injection of dibutyryl cyclic adenosine 3',5'-monophosphate increases hypothalamic levels of neuropeptide Y. Brain Res., 660, 323-328.

Akabayashi, A.; Zaia, C.T.B.V.; Koenig, J.I.; Gabriel, S.M.; Silva, I. \& Leibowitz, S.F. (1994), Diurnal rhythm of galanin-like immunoreactivity in the paraventricular and suprachiasmatic nuclei and other hypothalamic areas. Peptides, 15, 1437-1444.

Michalany, J. (1980), Inclusão e execução dos cortes em parafina. In: Técnica histológica em anatomia patológica (Ed.) J. Michalany, E.P.U., São Paulo. Pp, 62-97.

Paxinos, G. \& Watson, C. (1986), The Rat Brain in stereotaxic coordenates. Academic Press, New York.

Palkovits, M. (1973), Isolated removal of hypothalamic or other brain nuclei of the rat. Brain Res., 59, 449-450.

Zaia, C.T.B.V. (1984), Alguns efeitos precoces e tardios da lesão do hipotálamo ventromedial do rato. Dissertação de $\mathrm{MsC}$, Escola Paulista de Medicina-Universidade Federal de São Paulo, São Paulo, Brasil.

Zaia, C.T.B.V. (1991), Efeito hiperglicemiante da estimulação elétrica ou química do núcleo dorsomedial do hipotálamo. Tese de PhD, Escola Paulista de Medicina-Universidade Federal de São Paulo, São Paulo, Brasil.

Zaia, C.T.B.V.; Gaziri, L.C.J.; Zaia, D.A.M.; Delattre, E.; Dolnikoff, M.S. \& Timo-Iaria, C. (1997), Effect of chemical stimulation of the dorsomedial hypothalamic nucleus on blood plasma glucose, triglycerides and free fatty acids in rats. Brain Res. Bull., 42 (3), 195-198.

Zaia, C.T.B.V.; Oller do Nascimento, C.M.P.; TimoIaria, C. \& Dolnikoff, M.S. (1987), Time course of insulin, corticosterone and metabolic changes caused by lesion of the ventromedial hypothalamus in the rat. Physiol. Behav., 39 (6), 707-714.
Received: October 13, 1997; Revised: April 01, 1998; Accepted: May 25, 1998. 